University at Albany, State University of New York

Scholars Archive

Psychology Faculty Scholarship

Psychology

2011

\title{
Prospective Changes In Attributions Of Self-Blame And Social Reactions To Women's Disclosures Of Adult Sexual Assault
}

\author{
Cynthia J. Najdowski \\ University at Albany, State University of New York, cnajdowski@albany.edu \\ Sarah E. Ullman \\ The University of Illinois at Chicago
}

The University at Albany community has made this article openly available.

Please share how this access benefits you.

Follow this and additional works at: https://scholarsarchive.library.albany.edu/psychology_fac_scholar

Part of the Clinical Psychology Commons, Counseling Commons, Counseling Psychology Commons, Criminology and Criminal Justice Commons, Domestic and Intimate Partner Violence Commons, Gender and Sexuality Commons, and the Social Psychology Commons

\section{Recommended Citation}

Najdowski, Cynthia J. and Ullman, Sarah E., "Prospective Changes In Attributions Of Self-Blame And Social Reactions To Women's Disclosures Of Adult Sexual Assault" (2011). Psychology Faculty Scholarship. 20.

https://scholarsarchive.library.albany.edu/psychology_fac_scholar/20

This Article is brought to you for free and open access by the Psychology at Scholars Archive. It has been accepted for inclusion in Psychology Faculty Scholarship by an authorized administrator of Scholars Archive.

Please see Terms of Use. For more information, please contact scholarsarchive@albany.edu. 
PRE-PRINT. This paper is not the copy of record and may not exactly replicate the authoritative document published in the journal.

Running head: ATTRIBUTIONS AND SOCIAL REACTIONS

Prospective Changes in Attributions of Self-Blame and Social Reactions to Women's Disclosures of

Adult Sexual Assault

Sarah E. Ullman

Cynthia J. Najdowski

University of Illinois at Chicago

Sarah E. Ullman, Ph.D.

Professor

Department of Criminology, Law, \& Justice University of Illinois at Chicago

1007 West Harrison Street, M/C 141

Chicago, IL 60607

seullman@uic.edu

312-996-6679
Cynthia J. Najdowski, M.A.

Graduate Student

Department of Psychology

University of Illinois at Chicago

1007 West Harrison Street, M/C 285

Chicago, IL 60607

cnajdo2@uic.edu

312-996-3036 
This research was supported by a grant from NIAAA \#13455 to Sarah E. Ullman. We acknowledge Henrietta Filipas, Stephanie Townsend, Laura Starzynski, and Kelly Kinnison for assistance with data collection. 


\begin{abstract}
The present longitudinal study examined relations between self-blame attributions and social reactions to disclosure in a community sample of adult sexual assault victims $(N=555)$. Cross-lagged panel analyses showed that neither characterological self-blame nor behavioral self-blame related to negative social reactions over the 1-year follow-up period. In contrast, characterological but not behavioral self-blame predicted fewer positive reactions over time. Although positive reactions did not reduce self-blame, negative reactions led to greater characterological, but not behavioral, self-blame during the course of the study. Thus, relations between self-blame and social reactions were not reciprocal but rather quite complex. The effects of victims' coping strategies and sexual revictimization were also assessed. Implications for research, treatment, and intervention are discussed.
\end{abstract}

Key words: sexual assault, attributions, self-blame, social reactions, disclosure, revictimization, longitudinal study 
Prospective Changes in Attributions of Self-Blame and Social Reactions to Women's Disclosures of Adult Sexual Assault

Research shows that attributions of self-blame and negative social reactions to disclosures are each associated with sexual assault victims' recovery outcomes (Borja, Callahan, \& Long, 2006; Campbell et al., 1999; Frazier, 2003; Frazier, Mortensen, \& Steward, 2005; Koss, Figueredo, \& Prince, 2002; Littleton \& Breitkopf, 2006; Najdowski \& Ullman, 2009; Ullman \& Filipas, 2001). Few studies have examined relations between self-blame attributions and social reactions to disclosure of assault simultaneously, however, and those that have are limited by having used cross-sectional study designs. For example, in a cross-sectional study of adult rape victims from the community, Wyatt, Newcomb, and Notgrass (1991) showed that self-blame was correlated with fewer supportive responses from persons told about the rape and more involvement of formal authorities, who typically have negative responses to victims (Golding, Siegel, Sorenson, Burnam, \& Stein, 1989; Ullman, 1996). Although research shows that self-blame and social reactions to disclosures are related, the direction of effects between the variables remains unclear.

One possibility is that support sources' negative reactions to disclosures (e.g., blaming the victim) may cause women to feel that it was their fault they were sexually assaulted. For example, although victims frequently receive both negative and positive reactions from disclosure sources (Ullman, 1999), according to the social negativity hypothesis from the stress and coping literature, victims may give more weight to negative reactions than positive reactions, and negative reactions can then elicit strong emotional reactions from the victim (Major, Zubek, Cooper, \& Cozzarelli, \& Richards, 1997). In addition, negative social reactions could reinforce or exacerbate already existing feelings of self-blame common in victims of this crime, consistent with the affect matching hypothesis (Major et al., 1997). In fact, some cross-sectional research has found that receiving negative social reactions leads to greater self-blame in victims (e.g., Littleton \& Breitkopf, 2006; Ullman, Townsend, Filipas, \& Starzynski, 2007).

Research has focused much more on negative social reactions than on positive social reactions, but it is also possible that positive reactions reduce victims' attributions of self-blame. Social support and positive social relationships have been shown to promote self-worth and well-being through being accepted and cared for by others (Cohen \& Wills, 1985; Flannery, 1990; Major et al., 1997). In addition, social support appears to influence appraisals of trauma severity and perceptions of control over trauma and recovery (Cohen \& Wills, 1985; Frazier, Steward, \& Mortensen, 2004; Guay, Billette, \& Marchand, 2006). Thus, receiving positive 
reactions, such as validation and support, in response to disclosures may make it less likely for victims to think it was their fault they were assaulted. In support, McMillen and Zuravin (1998) found that greater perceived social support predicted self-reported decreases in self-blame in victims of child sexual abuse.

Although these cross-sectional findings are suggestive, it is also likely that self-blame affects the social reactions victims receive in response to assault disclosures. First, women who blame themselves for having been assaulted may convey those feelings to support sources when they disclose their assault experiences. In response, support sources may be more likely to react with blaming or other negative reactions, particularly if they subscribe to rape myths that hold victims responsible for rape (Frese, Moya, \& Megías, 2004; Krahé, 1988). Further, in response to a victim's self-blame, a support source may be less likely to suggest the assault was not the victims' fault or to have other positive reactions. In support, prior research has shown that how a victim appears to be coping may affect the willingness of social network members to provide support (DunkelSchetter \& Skokan, 1990; Silver, Wortman, \& Crofton, 1990). In addition, an experimental study conducted by Thornton and colleagues (1988) revealed that participants who read a fictitious victim's account of being sexually assaulted were significantly more likely to attribute responsibility for the assault to the victim if she blamed either her character or behavior than if she blamed chance for the assault. Both laypeople and rape crisis counselors demonstrated this bias, and men in particular had more blaming responses to victims' self blame (see also Anderson \& Lyons, 2005). Similarly, Brown and Testa (2008) showed that participants who read about others' negative reactions to a sexual assault victim had less supportive reactions compared to those who read interviews depicting neutral or positive reactions, further suggesting that witnessing others' blame may influence one's own responses to a victim. More direct evidence comes from Ullman's (1996) cross-sectional study of sexual assault victims which showed that self-blame predicted fewer positive social reactions. Thus, greater attributions of self-blame may be associated with receiving more negative reactions and fewer positive reactions from support sources as victims disclose over time.

Longitudinal research has yet to test these competing hypotheses simultaneously in a sample of women sexual assault victims, but, theoretically, it makes sense to expect that relations between self-blame attributions and social reactions to disclosures may be bi-directional. Because cross-lagged panel models can yield evidence of causality to resolve questions about reciprocal causality between variables (Martens \& Haase, 2006), we used cross-lagged panel models to test and compare relations between self-blame and social reactions over time in a sample of community women victims. These analyses allowed us to determine whether (a) attributions of self- 
blame are a stronger predictor of social reactions, (b) social reactions have a stronger influence on self-blame, or (c) each influences the other over time vice versa. We predicted that attributions and social reactions would influence each other over time. Further, because most past research suggests that negative social reactions have a strong negative effect on victims' symptoms whereas positive reactions have a weak positive or nonsignificant effect (for review, see Ullman, 2010), we expected the effect of negative reactions on self-blame to be stronger than that of positive reactions.

\section{Types of Self-Blame: Characterological vs. Behavioral}

Self-blame may be categorized as either characterological, in which victims blame their character for the sexual assault (e.g., it happened because I am a bad person), or behavioral, in which victims blame their behavior for the assault (e.g., it happened because of what I did). Although research with samples of assault victims has shown that both characterological self-blame and behavioral self-blame are related to poorer recovery (e.g., Frazier, 2003; Frazier \& Schauben, 1994; Littleton \& Breitkopf, 2006), Littleton, Magee, and Axsom's (2007) meta-analysis on self-blame following trauma suggests that characterological self-blame and behavioral self-blame are distinct constructs. Studies assessing both types of self-blame typically find stronger effects on distress for characterological self-blame than for behavioral self-blame (Breitenbecher, 2006; Hill \& Zautra, 1989; Koss et al., 2002; Ullman, Filipas, et al., 2007). In theory, attributions to one's character have more deleterious outcomes than attributions to one's behavior, because character traits are stable whereas behavior can be changed and future victimization can perhaps be avoided (Janoff-Bulman, 1979).

Do relations with social reactions to disclosures also differ depending on whether self-blame is characterological or behavioral? To answer this question, we tested our path model separately with each type of self-blame, expecting to find similar but stronger relations between characterological self-blame and social reactions than behavioral self-blame and social reactions.

\section{Coping Strategies, PTSD Symptom Severity, and Sexual Revictimization}

Victims' recovery from assault is a complex phenomenon, so it is important to consider other factors that might relate to victims' attributions of self-blame and the social reactions they receive from people to whom they disclose. One such factor involves the strategies victims engage in to cope with sexual assault. Maladaptive coping strategies, those that reduce distress by denial or withdrawal without actually addressing the source of distress itself (Carver, Scheier, \& Weintraub, 1989), are consistently associated with worse psychological symptomatology in sexual assault victims (e.g., Gutner, Rizvi, Monson, \& Resick, 2007; Ullman, Townsend, et 
al., 2007; Valentiner, Riggs, Foa, \& Gershuny, 1996). Cross-sectional research has shown both that (a) selfblame and negative social reactions predict greater engagement in maladaptive coping strategies in sexual assault victims (e.g., avoidance coping, Littleton \& Breitkopf, 2006; Ullman, Townsend, et al., 2007) and (b) that avoidant coping predicted greater self-blame in a sample of child sexual abuse victims (Quas, Goodman, \& Jones, 2003) and more negative social reactions in victims of adult sexual assault (Ullman, 1996). Victims' adaptive coping strategies (i.e., approach forms of coping aimed at alleviating distress such as support seeking or problem solving) may also influence self-blame and social reactions to disclosures. Some cross-sectional research shows that these forms of coping are associated with greater psychological distress in victims (Najdowski \& Ullman, 2009), presumably because greater distress necessitates the need for greater coping, but other research shows such strategies reduce distress over time (e.g., Gutner et al., 2007). Few studies have examined the potentially protective effects of adaptive coping on victims' self-blame or the social reactions they receive, although one study found that characterological self-blame related to less expressive coping (i.e., an adaptive coping strategy) in a sample of child sexual abuse victims (Arata, 1999). Although the direction of relations among coping, self-blame, and social reactions remains unclear, we accounted for victims' maladaptive and adaptive coping strategies in our models. We expected that victims' maladaptive coping would elicit more self-blame, more negative reactions, and fewer positive reactions from disclosure sources, whereas adaptive coping would relate to less self-blame, fewer negative reactions, and more positive reactions.

Research on sexual assault victims shows that PTSD is also associated with self-blame and social reactions to disclosures (Littleton \& Breitkopf, 2006; Ullman \& Filipas, 2001). More symptomatic victims may be more likely to feel at fault for their assaults and to receive more negative responses and less support from other people, who may be more threatened by their poorer functioning. Thus, we also included PTSD symptom severity in our model. We expected PTSD symptom severity to relate to more self-blame, more negative reactions, and fewer positive reactions.

Because sexual revictimization is common in sexual assault victims (Classen, Palesh, \& Aggarwal, 2005) and relates to other factors studied here (i.e., attributions, social reactions, coping, and PTSD), we also included this major event in our models. Cross-sectional and longitudinal research suggests that self-blame for a sexual victimization experience is a risk factor for future sexual assault (Arata, 2000; Miller, Markman, \& Handley, 2007). It is possible that victimized women who blame themselves experience distress and consequently engage in maladaptive coping strategies (e.g., drinking to cope with distress) and/or more risky 
behaviors (e.g., sexual risk taking), thereby increasing their exposure to potential perpetrators. Therefore, we expected that revictimization would be predicted by self-blame, PTSD symptom severity, and maladaptive coping. We also expected adaptive coping to relate to less revictimization, based on research showing that assertiveness and social support seeking may reduce victims' risk of experiencing another sexual assault (Livingston, Testa, \& VanZile-Tamsen, 2007). In turn, we expected that revictimization would predict more self-blame, based on some evidence that victims of sexual assault in childhood and adulthood blame themselves more than those assaulted in only one life phase (Filipas \& Ullman, 2006; Ullman, Filipas, Townsend, \& Starzynski, 2007). Finally, because support sources may be more likely to have blaming responses and less likely to respond with supportive reactions if victims have had multiple assault experiences, we also expected that women who are revictimized will receive more negative reactions and fewer positive reactions compared to women who are not revictimized.

\section{Methods}

\section{Participants and Procedure}

The present longitudinal study analyzed data from a large, diverse sample of adult sexual assault victims who completed two self-report mail surveys administered 1 year apart. Advertisements in local newspapers and flyers distributed throughout area college campuses, community sites (e.g., bookstores), mental health agencies, and rape crisis centers invited women aged 18 or older with unwanted sexual experiences since age 14 to participate in a confidential mail survey. Interested women callers were mailed the initial survey (i.e., T1), with a cover letter, information sheet describing the study, a list of community resources for women victims of violence, and a postcard to return if they were interested in participating in the 1-year follow-up survey (i.e., T2). Women provided informed consent before participation and received $\$ 20$ for completing the T1 survey. Of those women who requested the initial survey, 1,084 returned it - a 90\% response rate. Most women $(n=909)$ who completed the T1 survey expressed an interest in completing the follow-up survey.

Approximately 1 year after they completed the T1 survey, participants were mailed the second survey with an up-to-date community resource sheet. A 1-year interval was deemed appropriate to capture social reactions to subsequent disclosures because victims commonly delay disclosing for months or years, often because they blame themselves for having been assaulted (for review, see Ullman, 2010). Thus, we expected that some women who responded to the advertisements would be ready to talk about their assaults and/or that completing the T1 survey might trigger some women to disclose. In addition, women who had disclosed 
previously might disclose to additional support sources during the interval. Women received another $\$ 20$ for completing the T2 survey.

T2 surveys were returned by 625 women - a $69 \%$ response rate. Including only respondents who reported an adult sexual assault at T1 $(n=969)$, we compared women who completed only our T1 survey $(n=$ $414)$ with those who completed both the T1 and T2 surveys $(n=555)$ : They did not differ significantly on any demographic or study variables (all $t \mathrm{~s}[284-957]=-1.87-1.31, p \mathrm{~s} \geq .06$; all $\chi^{2} \mathrm{~s}[1-7,937-966] \leq 7.75, p \mathrm{~s} \geq .11$ ). Our final sample for the purposes of this article included 555 women who reported an adult sexual assault at T1 and who completed both waves of data collection. All participants were treated in accordance with the ethical guidelines of the university institutional review board.

\section{Measures}

Sample demographics. At T1, participants reported their age $(M=33, S D=11)$, education $(14 \%$ completed less than 12th grade, $13 \%$ graduated high school, and $72 \%$ had at least some college), school status (27\% were students), employment status ( $51 \%$ were employed), sexual orientation ( $75 \%$ were heterosexual, $7 \%$ were lesbian, $13 \%$ were bisexual, and $5 \%$ were unsure), marital status (57\% were single, $28 \%$ were married/cohabitating, $14 \%$ were separated/divorced, and $1 \%$ were widowed), parental status ( $43 \%$ had children), ethnicity (38\% were Caucasian, $45 \%$ were African American, $6 \%$ were Hispanic, $2 \%$ were Asian, and $7 \%$ were of other ethnicities), and household income (36\% earned $\$ 10,000$ or less, 54\% earned between $\$ 10,001$ and $\$ 50,000$, and $9 \%$ earned more than $\$ 50,000) .^{1}$

Adult sexual assault and revictimization. Adult sexual assault at age 14 years or older was assessed dichotomously (yes/no) at T1 using the Sexual Experiences Survey (SES; Koss, Gidycz, \& Wisniewski, 1987). The SES has reported internal consistency reliability of .69 and test-retest reliability at 1 week apart of 93\% (Koss \& Gidycz, 1985). This sample includes only women who reported sexual assault at T1. Rape, experienced by $76 \%$ of women, was defined by questions assessing vaginal, oral or anal intercourse without consent by force or threat of force or when the victim was intoxicated. Attempted rape, reported by $10 \%$ of women, was defined as the same experiences except that the items were worded the "man tried to make you have sex" but "that intercourse did not occur." Sexual coercion, experienced by $10 \%$ of women, was defined by sexual intercourse subsequent to use of verbal pressure or misuse of authority, but no threats of force or actual physical force were used. Sexual contact, reported by $4 \%$ of women, was defined by reports of unwanted fondling or kissing that did not involve attempted penetration subsequent to verbal pressure, misuse of authority, threats of harm or actual 
physical force. Women who had experienced multiple sexual assaults were asked to report only on the most serious assault.

Thirty-five percent of victims reported that they were drinking or using drugs before the assault (yes/no). Women were on average $21(S D=7)$ years old at the time of the assault, and reported that their assaults occurred an average of $13(S D=11)$ years ago. Revictimization was assessed with the SES on the T2 survey, identifying 248 women ( $45 \%$ of the sample) who were sexually assaulted since the last survey (yes/no).

Attributions of self-blame. Two 5-item subscales of the Rape Attribution Questionnaire (Frazier, 2003), a valid and reliable self-report measure of sexual assault victims' attributions about why the assault occurred, assessed behavioral (e.g., "I should have resisted more," "I should have been more cautious") and characterological (e.g., "I am unlucky," "I am a careless person) self-blame at T1 and T2. Each item was answered with respect to the past 30 days on a scale ranging from 1 (strongly disagree) to 5 (strongly agree). Frazier (2003) reported subscale alpha coefficients ranging from .77-.89 and test-retest reliability coefficients ranging from .68-.80 in samples of women sexual assault victims. Responses were summed to calculate separate scales for behavioral self-blame (T1 $M=16.72, S D=5.30$, and T2 $M=15.89, S D=5.07$ ) and characterological self-blame (T1 $M=12.86, S D=4.55$, and $\mathrm{T} 2 M=12.43, S D=4.25)$ (scores on each scale ranged from 5 to 25 ).

Social reactions to disclosures. At T1, we asked women if they had ever told anyone about their assault experience. Seventy-nine percent of women $(n=438)$ had disclosed their assaults. Victims who had disclosed their assaults completed the Social Reactions Questionnaire (SRQ; Ullman, 2000), reporting how often they received 48 different social reactions from any support provider since the assault on a scale ranging from 0 (never) to 4 (always). Responses were averaged to create subscales assessing the frequency with which participants received positive reactions (e.g., emotionally or informationally supportive reactions such as "Held you or told you that you are loved" or "Helped you get information of any kind about coping with the experience") and negative reactions (e.g., blaming or stigmatizing reactions such as "Told you that you could have done more to prevent this experience from occurring" or "Said he/she feels you're tainted by this experience"). On average, women reported "sometimes" receiving positive reactions $(M=2.05, S D=.83$, range $=.00$ to 3.95$)$ and "rarely" receiving negative reactions $(M=1.01, S D=.66$, range $=.00$ to 3.37$)$.

At T2, we asked women if in the past year they had told anyone about the assault that they previously reported at T1. Fifty-one percent of women $(n=285)$ had disclosed their assaults since T1. The SRQ was administered again at $\mathrm{T} 2$, adapted so that women reported social reactions received since the last survey in 
response to disclosures of the initial sexual assault (T2 positive reactions: on average, "sometimes" received; $M$ $=1.98, S D=.80$, range $=.00$ to $4.00 ;$ T2 negative reactions: on average, "rarely" received; $M=.86, S D=.72$, range $=.00$ to 3.63). The SRQ has good test-retest reliability $(r \mathrm{~s}=.68$ to .77$)$ and evidence of several forms of validity as reported by Ullman (2000). The subscales were also reliable in this sample, with Cronbach's $\alpha$ s ranging from .92 to .94 across $\mathrm{T} 1$ and $\mathrm{T} 2$.

Coping. Participants completed the Brief COPE at T1, a 28-item self-report scale of coping strategies (Carver et al., 1989). Various coping strategies used in the past 30 days to cope with the assault were assessed with Likert items ranging from 1 (I didn't do this at all) to 4 (I did this a lot). The COPE has been widely used in studies of stressed populations and has adequate internal consistency reliability (all subscale alphas $\geq .60$ except one) and test-retest reliability $(\mathrm{r}=.46-.86)$. We created a composite measure of adaptive coping by computing the average of responses to the 18 items composing the active coping (e.g., "I concentrated my efforts on doing something about my situation"), use of emotional support (e.g., "I got comfort and understanding from someone"), use of instrumental support (e.g., "I got help/advice from other people"), venting (e.g., "I said things to let my unpleasant feelings escape"), positive reframing (e.g., "I looked for something good in what was happening"), planning (e.g., "I tried to come up with a strategy about what to do"), humor (e.g., "I made jokes about it"), acceptance (e.g., "I learned to live with it"), and religion (e.g., "I tried to find comfort in my religion or spiritual beliefs") subscales of the Brief COPE (Cronbach's $\alpha=.88$ ). On average, women reported using adaptive coping "a little bit" $(M=2.21, S D=.63$, range $=1.00$ to 3.83$)$. We also created a composite measure of maladaptive coping by averaging responses to the 6 items composing the selfdistraction (e.g., "I turned to work or other activities to take my mind off things"), denial (e.g., "I refused to believe that it happened"), and behavioral disengagement (e.g., "I gave up trying to deal with it") subscales of the Brief COPE (Cronbach's $\alpha=.72)$. On average, women reported using maladaptive coping "a little bit" $(M=$ $2.01, S D=.67$, range $=1.00$ to 4.00$)$.

PTSD symptom severity. The Posttraumatic Stress Diagnostic Scale (PDS; Foa, 1995) is a standardized 17-item self-report instrument used to provide a measure of PTSD symptom severity using DSM-IV criteria. At $\mathrm{T} 1$, on scales ranging from 0 (not at all) to 3 (almost always), women rated how often they had been bothered during the past 30 days by the following types of symptoms in relation to the assault: (a) reexperiencing/intrusion symptoms related to having upsetting thoughts, images, and nightmares; feeling as if the assault was happening again; and experiencing emotional and/or physical reactions when reminded of the 
assault; (b) avoidance/numbing symptoms related to trying not to think about the assault, not being able to remember part of the assault, having less interest in important activities, feeling distant from people, and/or feeling emotionally numb; and (c) hyperarousal symptoms related to having trouble falling or staying asleep, feeling irritable or angry, having trouble concentrating, and/or being overly alert or easily startled. The PDS has acceptable test-retest reliability $(\kappa=.74)$ for a PTSD diagnosis in assault victims over a two-week interval (Foa, Cashman, Jaycox, \& Perry, 1997). The measure was reliable in our sample $(\alpha=.93)$, with women on average reporting moderate symptom severity $(M=19.06 ; S D=12.38$, range $=0.00$ to 51.00$)$ (Foa, 1995).

\section{Results}

Using a structural equation modeling framework, we conducted an observed variables path analysis to test two cross-lagged, partially mediated models of self-blame and social reactions in sexual assault victims, one each for characterological self-blame and behavioral self-blame. In line with Kline's (2004) recommendations for structural equation modeling, all measures were univariate normal, with skew ranging from -.48 to 1.23 and kurtosis ranging from -.67 to 1.48 , and none of the first-order correlations exceeded \pm .50 (see Table 1), indicating that multicollinearity across variables was not a problem with these data at the measurement level.

Analyses were conducted with all 555 women using the maximum likelihood estimation procedure to replace missing data in AMOS, which is considered the best available estimation procedure (Allison, 2003). First, we tested preliminary models which included all hypothesized paths. Variables that were significantly correlated were allowed to covary in the models, although paths representing T1 associations are not discussed. Based on the statistical significance of the path coefficients, nonsignificant paths $(p>.05)$ were removed.

\section{Characterological Self-Blame}

The initial model testing relations of characterological self-blame with all hypothesized paths specified provided a good fit to the data, $\chi^{2}(5,555)=5.20, p=.31$, IFI $=1.00, \mathrm{NFI}=.99$, and RMSEA $=.02$. To identify the most parsimonious model, adaptive coping was deleted because it did not have a significant effect on revictimization or T2 variables and, in total, 17 nonsignificant paths were removed. Specifically, in addition to deleting paths from adaptive coping to revictimization, T2 characterological self-blame, T2 negative reactions, and T2 positive reactions, we also deleted paths from (a) T1 characterological self-blame to revictimization and T2 negative reactions; (b) T1 negative reactions to revictimization and T2 positive reactions; (c) T1 positive reactions to T2 characterological self-blame; (d) maladaptive coping to revictimization, T2 characterological self-blame, and T2 positive reactions; (e) PTSD symptom severity to T2 characterological self-blame, T2 
negative reactions, and T2 positive reactions; and (f) revictimization to T2 characterological self-blame and T2 positive reactions. The resulting model (see Figure 1) also had sufficiently good fit, $\chi^{2}(17,555)=21.13, p=.22$, $\mathrm{IFI}=1.00, \mathrm{NFI}=.97$, and $\mathrm{RMSEA}=.02$.

Controlling for T1 levels of characterological self-blame and social reactions, there was no effect of characterological self-blame on T2 negative reactions. As predicted, however, T1 characterological self-blame predicted significantly fewer positive reactions at $\mathrm{T} 2$. Further, although $\mathrm{T} 1$ positive reactions did not reduce $\mathrm{T} 2$ characterological self-blame, T1 negative reactions increased T2 characterological self-blame, as predicted. T1 positive reactions also predicted more T2 negative reactions. In addition, characterological self-blame remained significantly correlated with social reactions at $\mathrm{T} 2$. These results suggest that the prospective relations between characterological self-blame and social reactions are not bidirectional but instead are rather specific and complex.

The only significant effect of T1 maladaptive coping was to increase the number of negative reactions received in response to disclosures between surveys. As predicted, although PTSD symptom severity did not have a direct effect on T2 characterological self-blame or social reactions, having more severe PTSD symptoms at T1 was positively related to revictimization between surveys. Revictimization in turn predicted more negative reactions in response to disclosures of the $\mathrm{T} 1$ assault, also as predicted. Revictimization did not relate to $\mathrm{T} 2$ measures of positive reactions or characterological self-blame, however. Of interest, $\mathrm{T} 1$ positive reactions predicted less revictimization.

\section{Behavioral Self-Blame}

The initial model testing relations of behavioral self-blame with all hypothesized paths specified provided a good fit to the data, $\chi^{2}(7,555)=7.40, p=.39, \mathrm{IFI}=1.00, \mathrm{NFI}=.99$, and $\mathrm{RMSEA}=.01$. To identify the most parsimonious model, 17 nonsignificant paths $(p>.05)$ were removed. Specifically, we deleted paths from (a) T1 behavioral self-blame to revictimization, T2 negative reactions, and T2 positive reactions; (b) T1 negative reactions to revictimization, T2 behavioral self-blame, and T2 positive reactions; (c) T1 positive reactions to T2 behavioral self-blame; (d) maladaptive coping to revictimization, T2 behavioral self-blame, and T2 positive reactions; (e) adaptive coping to revictimization, T2 behavioral self-blame, and T2 negative reactions; (f) PTSD symptom severity to T2 behavioral self-blame, T2 negative reactions, and T2 positive reactions; and (g) revictimization to T2 positive reactions. The resulting model (see Figure 2) also had sufficiently good fit, $\chi^{2}(25,555)=21.38, p=.67, \mathrm{IFI}=1.00, \mathrm{NFI}=.98$, and $\mathrm{RMSEA}=.00$. 
Controlling for T1 levels of behavioral self-blame and social reactions, contrary to our expectations, T1 behavioral self-blame did not predict T2 social reactions, neither negative nor positive, nor did T1 social reactions relate to $\mathrm{T} 2$ behavioral self-blame. $\mathrm{T} 1$ positive reactions, however, predicted more $\mathrm{T} 2$ negative reactions. Behavioral self-blame and positive reactions were no longer significantly correlated at T2.

Neither T1 maladaptive nor adaptive coping related to T2 behavioral self-blame. In partial support of our hypotheses, T1 maladaptive coping predicted significantly more T2 negative reactions, but not fewer positive reactions. $\mathrm{T} 1$ adaptive coping predicted significantly more $\mathrm{T} 2$ positive reactions, but not fewer negative reactions. As predicted, although PTSD symptom severity did not have a direct effect on T2 behavioral selfblame or social reactions, having more severe PTSD symptoms at T1 was positively related to revictimization between surveys. Revictimization in turn predicted more T2 behavioral self-blame and more negative reactions in response to disclosures of the $\mathrm{T} 1$ assault, also as predicted. Revictimization did not relate to $\mathrm{T} 2$ positive reactions, however. Again, T1 positive reactions predicted less revictimization.

Discussion

Past cross-sectional research has shown associations between sexual assault victims' attributions of selfblame and the social reactions they receive in response to disclosures (Ullman, 1996; Ullman, Townsend, et al., 2007), but the present study was the first to examine the effects of these variables on each other over time in an effort to determine the direction of causality. Next, we will discuss our findings related to (a) prospective relations between the two types of self-blame attributions and social reactions, (b) the effects of maladaptive and adaptive coping in our model, (c) the effects of PTSD symptom severity, and (d) predictors and consequences of revictimization.

\section{Prospective Relations between Self-Blame Attributions and Social Reactions}

First, we were interested in whether self-blame predicted subsequent social reactions to victims' disclosures of the T1 assault. Neither characterological self-blame nor behavioral self-blame prospectively related to negative social reactions over the 1-year follow-up period in this study. In contrast, greater characterological self-blame (but not behavioral self-blame) predicted receipt of fewer positive reactions over time, consistent with experimental research (Brown \& Testa, 2008; Thornton et al., 1988). This finding may suggest that low self-worth and/or poor psychological functioning, which are both common in victims who attribute assaults to their character (Littleton \& Breitkopf, 2006; Koss et al., 2002), may lead others to react less positively to survivors over time. In addition, the tendency of victims who make characterological attributions 
for their assaults to receive fewer positive reactions from support sources should be considered in light of Feiring, Rosenthal, and Taska's (2000) finding that adolescents' self-blaming attributions for sexual abuse related to lower satisfaction with support from friends and less perceived self-competence for being in relationships assessed 1 year later. Although Feiring and colleagues did not differentiate between characterological and behavioral self-blame, their results suggest that self-blame has a deleterious effect on the quality of victims' social support networks over time. The null effects of behavioral self-blame on either negative or positive social reactions also fit into this framework: Assault victims who blame their behavior for assaults tend to engage in social withdrawal as a coping mechanism (Frazier et al., 2005), so this form of blame may not relate to subsequent social reactions because survivors do not have as much contact with others or discuss the assault.

We were also interested in testing whether social reactions influenced self-blame over time. Positive reactions did not reduce self-blame, neither characterological nor behavioral, although receiving negative reactions led to greater characterological but not behavioral self-blame during the course of the study. This is in contrast to McMillen and Zuravin's (1998) finding that perceived social support related to decreases in child sexual abuse victims' self-blame. Their study was cross-sectional, however, and compared victims' retrospective reports of self-blame during childhood to their current self-blame. Thus, victims' current levels of support or self-blame may have biased their retrospective reports. Our finding is, however, consistent with cross-sectional research showing that positive reactions have little impact on recovery outcomes (Ullman, 1999), whereas negative reactions may reinforce a negative sense of self-worth as well as a victim's tendency to blame their character, a pattern also revealed in cross-sectional analyses of these data (Ullman, 1996; Ullman, Townsend et al., 2007). This finding supports both Major and colleagues' (1997) social negativity hypothesis, which asserts that negative interactions predict negative outcomes to a greater extent than do positive interactions, and affect matching hypothesis, which asserts that negative social interactions have a strong impact on negative aspects of one's mental health, in this case victims' beliefs that they were assaulted because of characterological flaws.

Although behavioral self-blame was no longer significantly correlated with social reactions at T2, characterological self-blame remained negatively correlated with positive social reactions. Koss and Figueredo (2004) found that both characterological and behavioral self-blame decreased significantly over 2 years in a sample of sexual assault victims (see also Littleton et al., 2007), but decreases in behavioral self-blame were 
more strongly related to victims' recovery. Further, characterological self-blame had a strong effect on establishing initial levels of maladaptive personal beliefs related to trauma (e.g., safety, control), which in turn led to greater psychological distress. Thus, characterological self-blame may indirectly reduce positive social reactions over time by increasing victims' maladaptive beliefs, which are then communicated to support sources during disclosures. Further, negative social reactions received at T1 may reinforce victims' maladaptive beliefs and thereby influence characterological self-blame. This may explain why our model only accounted for part of the associations between characterological self-blame and social reactions.

In both models, victims who received more positive reactions at $\mathrm{T} 1$ received more negative reactions at T2. This is consistent with past cross-sectional research showing positive correlations between positive and negative social reactions (e.g., Borja et al., 2006). Such associations could result if women's positive disclosure experiences lead them to disclose to more people and to receive more reactions of all kinds, although we could not test this because we did not measure the number of people women disclosed to between surveys. In crosssectional studies, however, victims who tell more people receive more positive and negative social reactions from others (Ullman, 2000).

\section{Effects of Maladaptive and Adaptive Coping}

Neither maladaptive nor adaptive coping related to either type of self-blame over time, in contrast to cross-sectional research showing such relations (Littleton \& Breitkopf, 2006; Ullman, 1996). In both models, victims who engaged in greater maladaptive coping reported receiving more negative reactions over time, but not fewer positive reactions. This finding is consistent with stress and coping theorists' argument that a victim's coping strategies affect the level of support they get from social networks, and that maladaptive coping may elicit less support and/or more negative responses from others (Dunkel-Schetter \& Skokan, 1990; Silver et al., 1990).

Adaptive coping was not significantly associated with positive reactions in the model predicting characterological self-blame, but results from the model examining relations of behavioral self-blame suggested that victims who engaged in greater adaptive coping received more positive reactions over time. Perhaps victims are perceived by others to be coping more effectively when attributions are focused on one's behavior which is more amenable to change than is one's character. It is also possible that in our study the negative effect of characterological self-blame on reducing positive social reactions was stronger than the positive effect of adaptive coping on increasing positive social reactions, preventing the effect from emerging in that model. Even 
so, these results suggest that adaptive coping may be important for increasing positive support for some victims. Littleton (2007) suggested that victims' adaptive coping may increase positive support from others because it improves victims' feelings of self-worth. Future research should seek to better understand the mechanisms by which adaptive coping improves victims' outcomes.

PTSD Symptom Severity

PTSD symptom severity did not have a direct effect on T2 self-blame or social reactions. This is consistent with others who have not found relations between PTSD and social reactions, although negative reactions have been shown to predict later PTSD (Andrews, Brewin, \& Rose, 2003; Zoellner, Foa, \& Brigidi, 1999). As predicted, however, having more severe PTSD symptoms at T1 was positively related to revictimization between surveys. The link between PTSD symptom severity and subsequent revictimization may result from distressed victims being less able to protect themselves when numbing or avoidance symptoms preclude their ability to detect risk (Marx \& Soller-Baillo, 2005). It is also possible that distressed victims who turn to risky behaviors such as substance use or increased sexual partners are more likely to be targeted by perpetrators (Logan, Walker, Cole, \& Leukefeld, 2002; Messman-Moore, Coates, Gaffey, \& Johnson, 2008). Alternatively, prior histories of sexual abuse may be responsible for this association, given past research suggesting that PTSD mediates the effect of child sexual abuse on adult sexual assault (Messman-Moore, Ward, \& Brown, 2008).

\section{Predictors and Consequences of Sexual Revictimization}

Although past research has suggested that post-assault self-blame is a risk factor for sexual revictimization (Arata, 2000; Miller et al., 2007), neither characterological nor behavioral self-blame predicted revictimization in our sample. There are a few possible explanations for our failure to replicate past results. First, Arata (2000) examined self-blame for child sexual abuse (Arata, 2000) and Miller and colleagues (2007) examined self-blame for adolescent sexual assault. In contrast, we studied self-blame for adult sexual assault. It is possible that, compared to younger victims, adult victims blame themselves less over time and/or have found better ways to cope and protect themselves from being revictimized. Alternatively, it is likely that the developmental impact of sexual victimization at an earlier age is more deleterious, particularly since childhood sexual abuse is more likely to be a repeated experience perpetrated by trusted others such as parents or caretakers. Betrayal trauma theory suggests that such early victimization by trusted others is more traumatic because the child is more dependent on the perpetrator for survival (Freyd, 1996). Thus, internalization of self- 
blame may be much greater and longer lasting for victims of child sexual abuse than for victims of adult sexual assault, who are more likely to experience a single incident of assault by an acquaintance. Past research also did not differentiate between characterological and behavioral self-blame as separate constructs, even though some research suggests that early abuse is related more strongly to characterological than behavioral self-blame for interpersonal violence (Andrews \& Brewin, 1990).

Another possibility is that PTSD symptom severity is a stronger correlate of revictimization than either type of self-blame when examined independently. Our finding that PTSD symptom severity relates to revictimization is consistent with other research suggesting that this form of psychological distress mediates relations between past and future victimization in women, both physical (e.g., Krause, Kaltman, Goodman, \& Dutton, 2006; Perez \& Johnson, 2008) and sexual (e.g., Noll, Horowitz, Bonanno, Trickett, \& Putnam, 2003; Ullman, Najdowski, \& Filipas, 2009). A novel contribution of this study, however, is the understanding that this effect holds true even when controlling for victims' self-blame and social reactions.

Although revictimization did not predict T2 characterological self-blame or T2 positive reactions, it did predict more $\mathrm{T} 2$ behavioral self-blame and more negative reactions in response to disclosures of the T1 assault, as predicted. It is interesting that victims' perceptions of their character as a nonmodifiable catalyst for their sexual assault experiences appear to be unaffected by sexual revictimization. In contrast, being revictimized may lead women to feel they are somehow behaving in a way that brings on their victimization. Behavioral selfblame may be reinforced in such victims who feel they should be able to change their behavior to avoid future assaults but who are unsuccessful in doing so. To the extent that revictimized women disclosed both T1 assaults and intervening assaults that occurred during the study, support sources might have reacted more negatively to them because support sources use the same reasoning and blame victims' behavior. These rationalizations are common, promulgated in society through rape myths that suggest women's behavior precipitates rape and that they are responsible and blameworthy for sexual assaults (Lonsway \& Fitzgerald, 1994). It is also possible that support sources respond negatively to disclosures because they feel threatened by women who have experienced multiple incidents of victimization. For instance, being faced with someone who has been re-assaulted may threaten one's beliefs about his or her own safety. Support providers may also feel unable to deal with the greater psychological distress that victims who have experienced multiple assaults may exhibit, especially if they are close to such victims (Ahrens \& Campbell, 2000; Ahrens, Cabral, \& Abeling, 2009; Davis \& Brickman, 1996). Alternatively, revictimized women may be victims of assaults perpetrated by intimate partners who also 
pose a threat to others around the victim or whose assaults are less likely to be viewed as legitimate and therefore result in more negative responses (Martin, Taft, \& Resick, 2007). Consistent with this, Andrews and Brewin (1990) reported that victims of marital violence were more likely to experience behavioral than characterological self-blame, although their results suggested that negative social reactions were more common for victims who blamed their character than those who blamed their behavior.

A striking finding was that $\mathrm{T} 1$ positive social reactions to victims' disclosures predicted less revictimization, demonstrating that positive reactions may play a protective role in preventing harmful assault sequelae. This finding might indicate that positive social support has a protective role in reducing risk of sexual assault revictimization, which suggests that strengthening support networks and access to effective formal services might reduce women's risk of revictimization. Such an explanation is in line other research showing that social support is protective against re-abuse in at least some victims of domestic violence (Goodman, Dutton, Vankos, \& Weinfurt, 2005). Further, positive social reactions have been shown to relate to posttraumatic growth (Borja et al., 2006), so the protective effect of positive reactions on reducing revictimization likelihood may be explained by fewer experiences of psychological distress and/or substance use that are known risk factors for revictimization.

\section{Caveats and Implications}

This study was the first to examine relations between self-blame and social reactions longitudinally. Our findings are important not only for understanding how social reactions received in response to disclosures influence victims' attributions over time as victims process the reactions and cope with their experiences, but also for understanding how victims' self-blame influences the way support providers respond to them, both initially and during subsequent interactions. Even so, this study was limited by having only two waves of data collection. In fact, having three or more waves of data collection would be required to establish causality among the variables studied here. Cross-lagged panel designs such as ours are useful for determining which variables are stronger temporal predictors of others, however, which is suggestive that certain variables are more likely the cause of others (Martens \& Haase, 2006).

Another limitation is that participants experienced assaults that varied in degree of severity, ranging from sexual contact to rape. Participants also varied at baseline in time since they had been sexually assaulted. To the extent that assault severity or time since assault influenced the relations assessed herein, such variation might have made it more difficult to find significant effects. This possibility seems unlikely, however, because a 
series of regressions predicting self-blame and social reactions with assault severity and time since assault included as control variables revealed no significant effects of those variables, and the pattern of effects reported here remained unchanged. In addition, cross-sectional analyses of these data suggest that victims' histories of childhood sexual abuse, other lifetime traumas, or substance use at the time of the assault might have prospectively affected the extent to which they blamed themselves for the assault as well as the strategies they engaged in to cope with the assault and/or social reactions they received in response to disclosures (Najdowski \& Ullman, 2009; Ullman \& Najdowski, 2010). Although victims did vary in assault severity, time since assault, victimization and trauma histories, substance use at the time of the assault, and various other factors that could relate to self-blame and social reactions, this large sample was also diverse in terms of ethnicity and socioeconomic status and it included victims who can be difficult to reach with traditional random sampling methods (e.g., women without telephones, in shelters). Despite variation among women in this nonrepresentative community sample, we found some support for our hypotheses that self-blame and social reactions relate to each other over time and that such relations depend on the type of self-blame assessed (i.e., characterological versus behavioral). In addition, many victims experienced a new assault over the 1-year study period allowing us to examine the prospective influence of revictimization on self-blame and social reactions. The results of this study can be used as the basis for future research that follows representative samples of victims immediately after assault to examine how attributions and self-blame and social reactions to disclosures evolve together over time.

A further limitation is that we assessed social reactions from any support provider but research suggests that self-blame may be related to social reactions from the first person disclosed to in particular (Pitts \& Schwartz, 1997), and negative responses from persons first told can silence victims from further disclosing to others (Ahrens, 2006). In addition, Borja and colleagues' (2006) findings suggest that whether the source of positive or negative reactions is a formal (e.g., doctor, therapist) or informal support member (e.g., friend, relative) may moderate the effect of reactions on posttraumatic outcomes. An additional caveat noted by Borja et al. is that the SRQ is a self-report measure of social reactions; thus, victims' reports may be affected by their experiences of distress or well-being at the time of assessment.

Our research suggests that future research should target interventions to reduce victims' use of maladaptive coping strategies, which are prospectively associated with more negative reactions from support sources. In addition, reducing victims' characterological self-blame and increasing their use of adaptive coping 
strategies may be associated with increased positive reactions from support sources. Given our findings that negative reactions increase characterological self-blame over time and that positive reactions have a protective effect on reducing revictimization likelihood, research should also focus on improving social support sources reactions to victims' disclosures. Such interventions could both (a) train victims to communicate with support sources about their needs and (b) teach support sources how to react in ways that facilitate victims' recovery.

Overall, our results support prior conclusions that characterological and behavioral self-blame are different constructs and relate uniquely to outcomes for sexual assault victims (e.g., Littleton et al., 2007). Characterological self-blame was an outcome and predictor of social reactions, whereas behavioral self-blame was not. Yet one commonality was that both types of self-blame perpetuated themselves over time (i.e., T1 attributions of self-blame were strong predictors of $\mathrm{T} 2$ attributions for both characterological and behavioral self-blame). This finding also should be considered in the context of other assault sequelae that were not included in our models (e.g., T2 PTSD symptom severity). That is, T2 attributions of self-blame and social reactions may mediate the effects of $\mathrm{T} 1$ measures of these variables, as well as $\mathrm{T} 1$ measures of coping and PTSD symptom severity, on victims' psychological distress.

Because self-blame is associated with poorer outcomes in victims, it is important for research to focus on treatment and intervention strategies aimed at modifying these maladaptive attributions. Research examining factors associated with victims' attributions of self-blame as well as coping strategies should inform such programs, as research with child sexual abuse victims suggests that these outcomes may be affected by individual differences (e.g., ethnicity, Feiring, Coates, \& Taska, 2001) and assault characteristics (e.g., abuse severity, Quas et al., 2003). Further, research with sexual assault victims suggests that having a history of sexual abuse may increase self-blaming attributions and affect the types of coping strategies victims' use (Arata, 1999), suggesting that research should be more inclusive in assessing victim's trauma histories rather than focusing just on sexual assault. Until interventions are developed to successfully reduce the incidence of sexual assault, it is crucial for researchers to understand the complex constellation of factors related to victims' recovery and to develop programs to facilitate victims' recovery based on empirical research. 


\section{Footnote}

${ }^{1}$ We conducted bivariate analyses to determine whether there were any associations between the demographic variables we assessed and T2 attributions of self-blame and social reactions. Because we had no a priori expectations regarding such associations, to be conservative, we set alpha at .001 for these analyses. There were no clear or consistent patterns of effects, but a few differences did emerge. Women who had children reported significantly less behavioral self-blame than did women who did not have children, $t(425)=3.56, p<$ .001. Compared to women who were less educated, women who were more educated received significantly fewer positive social reactions, $r(258)=-.24, p<.001$, and significantly fewer negative reactions, $r(257)=-.23$, $p<.001$, in response to disclosures. Finally, greater income was significantly associated with receiving fewer negative responses to disclosures, $r(256)=-.24, p<.001$. 


\section{References}

Ahrens, C. A. (2006). Being silenced: The impact of negative social reactions on the disclosure of rape. American Journal of Community Psychology, 38, 263-274.

Ahrens, C. A., Cabral, G., \& Abeling, S. (2009). Healing or hurtful: Sexual assault survivors' interpretations of social reactions from different support providers. Psychology of Women Quarterly, 33, 81-94.

Ahrens, C. A. \& Campbell, R. M. (2000). Assisting rape victims as they recover from rape: The impact on friends. Journal of Interpersonal Violence, 15, 959-986.

Anderson, I., \& Lyons, A. (2005). The effect of victims' social support on attributions of blame in female and male rape. Journal of Applied Social Psychology, 35, 1400-1417.

Andrews, B., \& Brewin, C. R. (1990). Attributions of blame for marital violence: A study of antecedents and consequences. Journal of Marriage and the Family, 52, 757-767.

Andrews, B., Brewin, C. R., \& Rose, S. (2003). Gender, social support, and PTSD in victims of violent crime. Journal of Traumatic Stress, 16, 421-427.

Arata, C. M. (1999). Coping with rape: The roles of prior sexual abuse and attributions of blame. Journal of Interpersonal Violence, 14, 62-78.

Arata, C. M. (2000). From child victim to adult victim: a model for predicting sexual revictimization. Child Maltreatment, 5, 28-38.

Arata, C. M., \& Burkhart, B. R. (1998). Coping appraisals and adjustment to nonstranger sexual assault. Violence Against Women, 4, 224-239.

Borja, S. E., Callahan, J. L., \& Long, P. J. (2006). Positive and negative adjustment and social support of sexual assault survivors. Journal of Traumatic Stress, 19, 905-914.

Breitenbecher, K. H. (2006). The relationships among self-blame, psychological distress, and sexual victimization. Journal of Interpersonal Violence, 21, 597-611.

Brown, A., \& Testa, M. (2008). Social influences on judgments of rape victims: The role of the negative and positive reactions of others. Sex Roles, 58, 490-500.

Campbell, R. M., Sefl, T., Barnes, H. E., Ahrens, C. E., Wasco, S. M., \& Zaragoza-Diesfeld, Y. (1999). Community services for rape survivors: Enhancing psychological well-being or increasing trauma? Journal of Consulting and Clinical Psychology, 67, 847-858.

Carver, C. S., Scheier, M. F., \& Weintraub, J. K. (1989). Assessing coping strategies: A theoretically based 
approach. Journal of Personality and Social Psychology, 56, 267-283.

Classen, C., Palesh, O., \& Aggarwal, R. (2005). Sexual revictimization: A review of the empirical literature. Journal of Trauma, Violence, and Abuse, 6, 103-129.

Cohen, S., \& Wills, T.A. (1985). Stress, social support, and the buffering hypothesis. Psychological Bulletin, 98, 310-357.

Davis, R. C., \& Brickman, E. (1996). Supportive and unsupportive aspects of the behavior of others toward victims of sexual and nonsexual assault. Journal of Interpersonal Violence, 11, 250-262.

Dunkel-Schetter, C., \& Skokan, L.A. (1990). Determinants of social support provision in personal relationships. Journal of Social and Personal Relationships, 7, 437-450.

Feiring, C., Coates, D. L., \& Taska, L. S. (2001). Ethnic status, stigmatization, support, and symptoms development following sexual abuse. Journal of Interpersonal Violence, 16, 1307-1329.

Feiring, C., Rosenthal, S., \& Taska, L. (2000). Stigmatization and the development of friendship and romantic relationships in adolescent victims of sexual abuse. Child Maltreatment, 5, 311-322.

Filipas, H. H., \& Ullman, S. E. (2006). Child sexual abuse, coping responses, self-blame, PTSD, and adult sexual revictimization. Journal of Interpersonal Violence, 21, 652-672.

Flannery, R. B., Jr. (1990). Social support and psychological trauma: A methodological review. Journal of Traumatic Stress, 3, 593-611.

Foa, E. B. (1995). Posttraumatic Stress Diagnostic Scale Manual. Minneapolis, MN: National Computer Systems, Inc.

Foa, E. B., Cashman, L., Jaycox, L., \& Perry, K. (1997). The validation of a self-report measure of PTSD: The Posttraumatic Stress Diagnostic Scale. Psychological Assessment, 9, 445-451.

Frazier, P. A. (2003). Perceived control and distress following sexual assault: A longitudinal test of a new model. Journal of Personality and Social Psychology, 84, 1257-1269.

Frazier, P. A., Mortensen, H., \& Steward, J. (2005). Coping strategies as mediators of the relations among perceived control and distress in sexual assault survivors. Journal of Counseling Psychology, 52, 267278.

Frazier, P. A., \& Schauben, L. J. (1994). Causal attributions and recovery from rape and other stressful life events. Journal of Social \& Clinical Psychology, 13, 1-14.

Frese, B., Moya, M., \& Megías, J. L. (2004). Social perception of rape: How rape myth acceptance modulates 
the influence of situational factors. Journal of Interpersonal Violence, 19, 143-161.

Freyd, J. J. (1996). Betrayal trauma: The logic of forgetting childhood abuse. Cambridge, MA: Harvard University Press.

Golding, J. M., Siegel, J. M., Sorenson, S. B., Burnam, M. A., \& Stein, J. A. (1989). Social support sources following sexual assault. Journal of Community Psychology, 17, 92-107.

Goodman, L. A., Dutton, M. A., Vankos, N., \& Weinfurt, W. (2005). Women's resources and use of strategies as risk and protective factors for re-abuse over time. Violence Against Women, 11, 311-336.

Guay, S., Billette, V., \& Marchand, A. (2006). Exploring the links between posttraumatic stress disorder and social support: Processes and potential research avenues. Journal of Traumatic Stress, 19, 327-338.

Gutner, C. A., Rizvi, S. L., Monson, C. M., \& Resick, P. A. (2007). Changes in coping strategies, relationship to the perpetrator, and posttraumatic distress in female crime victims. Journal of Traumatic Stress, 19, 813-823.

Hill, J. L., \& Zautra, A. J. (1989). Self-blame attributions and unique vulnerability as predictors of post-rape demoralization. Journal of Social and Clinical Psychology, 8, 368-375.

Kline, R. B. (1998). Principles and practice of structural equation modeling. New York: Guilford Press.

Koss, M. P., \& Figueredo, A. J. (2004). Change in cognitive mediators of rape's impact on psychosocial health across 2 years of recovery. Journal of Consulting and Clinical Psychology, 72, 1063-1072.

Koss, M. P., Figueredo, A. J., \& Prince, R. J. (2002). Cognitive mediation of rape's mental, physical, and social health impact: Tests of four models in cross-sectional data. Journal of Consulting and Clinical Psychology, 76, 926-941.

Koss, M. P., \& Gidycz, C. A. (1985). The sexual experiences survey: Reliability and validity. Journal of Consulting and Clinical Psychology, 53, 442-443.

Koss, M. P., Gidycz, C. A., \& Wisniewski, N. (1987). The scope of rape: Incidence and prevalence of sexual aggression and victimization in a national sample of students in higher education. Journal of Consulting and Clinical Psychology, 55, 162-170.

Krahé, B. (1988). Victim and observer characteristics as determinants of responsibility attributions to victims of rape. Journal of Applied Social Psychology, 18, 50-58.

Krause, E. D., Kaltman, S., Goodman, L., \& Dutton, M. A. (2006). Role of distinct PTSD symptoms in intimate partner reabuse: A prospective study. Journal of Traumatic Stress, 19, 507-516. 
Littleton, H. (2007). An evaluation of the coping patterns of rape victims: Integration with a schema-based information-processing model. Violence Against Women, 13, 789-801.

Littleton, H., \& Breitkopf, C. R. (2006). Coping with the experience of rape. Psychology of Women Quarterly, 30, 106-116.

Littleton, H., Magee, K., \& Axsom, D. (2007). A meta-analysis of self-attributions following three types of trauma: Sexual victimization, illness, and injury. Journal of Applied Social Psychology, 37, 515-538.

Livingston, J.A., Testa, M., \& VanZile-Tamsen, C. (2007). The reciprocal relationship between sexual victimization and sexual assertiveness. Violence Against Women, 13, 1-16.

Logan, T. K., Walker, R., Cole, J., \& Leukefeld, C. (2002). Victimization and substance abuse among women: Contributing factors, interventions, and implications. Review of General Psychology, 6, 325-397.

Lonsway, K. A., \& Fitzgerald, L. (1994). Rape myths: In review. Psychology of Women Quarterly, 18, 133-164.

Major, B., Zubek, J. M., Cooper, M. L., Cozzarelli, C., \& Richards, C. (1997). Mixed messages: Implications of social conflict and social support within close relationships for adjustment to a stressful life event. Journal of Personality and Social Psychology, 72, 1349-1363.

Martens, M. P., \& Haase, R. F. (2006). Advanced applications of structural equation modeling in counseling psychology research. Counseling Psychologist, 34, 878-911.

Martin, E. K., Taft, C. T., \& Resick, P. A. (2007). A review of marital rape. Aggression and Violent Behavior, $12,329-347$.

Marx, B. P., \& Soler-Baillo, J. M. (2005). The relationships among risk recognition, autonomic and selfreported arousal, and posttraumatic stress symptomatology in acknowledged and unacknowledged victims of sexual assault. Psychosomatic Medicine, 67, 618-624.

McMillen, C., \& Zuravin, S. (1998). Social support, therapy and perceived changes in women's attributions for their child sexual abuse. Journal of Child Sexual Abuse, 7, 1-15.

Messman-Moore, T., Coates, A. A., Gaffey, K. J., Johnson, C. F. (2008). Sexuality, substance use, and susceptibility to victimization: Risk for rape and sexual coercion in a prospective study of college women. Journal of Interpersonal Violence, 23, 1730-1746.

Messman-Moore, T., Ward, R., \& Brown, A. (2009). Substance use and PTSD symptoms impact the likelihood of rape and revictimization in college women. Journal of Interpersonal Violence, 24, 499-521.

Miller, A. K., Markman, K. D., \& Handley, I. M. (2007). Self-blame among sexual assault victims prospectively 
predicts revictimization: A perceived sociolegal context model of risk. Basic and Applied Social Psychology, 29, 129-136.

Najdowski, C. J., \& Ullman, S. E. (2009). PTSD and self-rated recovery among adult sexual assault survivors: The effects of traumatic life events and psychosocial variables. Psychology of Women Quarterly, 33, 4353.

Noll, J. G., Horowitz, L. A., Bonanno, G. A., Trickett, P. K., \& Putnam, F. W. (2003). Revictimization and selfharm in females who experienced childhood sexual abuse: Results from a prospective study. Journal of Interpersonal Violence, 18, 1452-1471.

Owens, G. P., \& Chard, K. M. (2006). PTSD severity and cognitive reactions to trauma among a college sample: An exploratory study. Journal of Aggression, Maltreatment \& Trauma, 13, 23-36.

Perez, S., \& Johnson, D. M. (2008). PTSD compromises battered women's future safety. Journal of Interpersonal Violence, 23, 635-651.

Pitts, V. L., \& Schwartz, M. D. (1997). Self-blame in hidden rape cases. In M. D. Schwartz (Ed.), Researching sexual violence against women: Methodological and personal perspectives (pp. 65-70). Thousand Oaks, CA: Sage.

Quas, J. A., Goodman, G. S., \& Jones, D. P. H. (2003). Predictors of attributions of self-blame and internalizing behavior problems in sexually abused children. Journal of Child Psychology and Psychiatry, 44, 723736.

Silver, R. C., Wortman, C. B., \& Crofton, C. (1990). The role of coping in support provision: The selfpresentational dilemma of victims of life crises. In I. G. Sarason, B. R. Sarason, \& G. R. Pierce (Eds.), Social support: An interactional view (pp. 397-426). New York: Wiley.

Thornton, B., \& Ryckman, R. M., Kirchner, G., Jacobs, J., Kaczor, L., \& Kuehnel, R. H. (1988). Reaction to self-attributed victim responsibility: A comparative analysis of rape crisis counselors and lay observers. Journal of Applied Social Psychology, 18, 409-422.

Ullman, S. E. (1996). Do social reactions to sexual assault victims vary by support provider? Violence and Victims, 11, 143-156.

Ullman, S. E. (1999). Social support and recovery from sexual assault: A review. Aggression and Violent Behavior: A Review Journal, 4, 343-358.

Ullman, S. E. (2000). Psychometric characteristics of the Social Reactions Questionnaire: A measure of 
reactions to sexual assault victims. Psychology of Women Quarterly, 24, 257-271.

Ullman, S. E. (2010). Talking about sexual assault: Society's response to survivors. Washington, D.C.: American Psychological Association Press.

Ullman, S. E., \& Filipas, H. H. (2001). Predictors of PTSD symptom severity and social reactions in sexual assault victims. Journal of Traumatic Stress, 14, 369-389.

Ullman, S. E., Filipas, H. H., Townsend, S. M., \& Starzynski, L. L. (2007). Psychosocial correlates of PTSD symptom severity in sexual assault survivors. Journal of Traumatic Stress, 20, 821-831.

Ullman, S. E., \& Najdowski, C. J. (2010). Understanding alcohol-related sexual assaults: Characteristics and consequences. Violence and Victims, 25, 29-44.

Ullman, S. E., \& Najdowski, C. J. (2009). Revictimization as a moderator of psychosocial risk factors for problem drinking in female sexual assault survivors. Journal of Studies on Alcohol and Drugs, 70, 4149.

Ullman, S. E., Najdowski, C. J., \& Filipas, H. H. (2009). Child sexual abuse, PTSD, and substance use: Predictors of revictimization in adult sexual assault survivors. Journal of Child Sexual Abuse, 18, 367385.

Ullman, S. E., Townsend, S. M., Filipas, H. H., \& Starzynski, L. L. (2007). Structural models of the relations of assault severity, social support, avoidance coping, self-blame, and PTSD among sexual assault survivors. Psychology of Women Quarterly, 31, 23-37.

Valentiner, D. P., Foa, E. B., Riggs, D. S., \& Gershuny, B. S. (1996). Coping strategies and posttraumatic stress disorder in female victims of sexual assault and nonsexual assault. Journal of Abnormal Psychology, $105,455-458$.

Wyatt, G. E., Newcomb, M., \& Notgrass, C. M. (1991). Internal and external mediators of women's rape experiences. In A. W. Burgess (Ed.), Rape and Sexual Assault III: A Research Handbook (pp. 29-55). New York: Garland.

Zoellner, L. A., Foa, E. B., \& Brigidi, B. D. (1999). Interpersonal friction and PTSD in female victims of sexual and nonsexual assault._Journal of Traumatic Stress, 12, 689-700. 
Table 1

First Order Correlations among Measures of Self-Blame, Social Reactions, PTSD, Coping, and Revictimization (ns = 261-546)

\begin{tabular}{|c|c|c|c|c|c|c|c|c|c|c|c|c|}
\hline & 1. & 2. & 3. & 4. & 5. & 6. & 7. & 8. & 9. & 10. & 11. & 12. \\
\hline 3. T1 Behavioral self-blame & & & - & $.54 * * *$ & $-.12 *$ & -.01 & .05 & .09 & $.10^{*}$ & $.12 * *$ & .02 & .03 \\
\hline 4. T2 Behavioral self-blame & & & & - & $-.11^{*}$ & -.08 & .05 & $.14^{*}$ & $.08^{\dagger}$ & .07 & .01 & $.14 * *$ \\
\hline 6. T2 Positive reactions & & & & & & - & -.04 & $.11^{\dagger}$ & .08 & .04 & $.29 * * *$ & -.02 \\
\hline 7. T1 Negative reactions & & & & & & & - & $.50 * * *$ & $.46^{* * *}$ & $.37 * * *$ & $.27 * * *$ & $.08^{\dagger}$ \\
\hline 8. T2 Negative reactions & & & & & & & & - & $.40 * * *$ & $.40 * * *$ & $.31 * * *$ & $.30 * * *$ \\
\hline 11. T1 Adaptive coping & & & & & & & & & & & - & .03 \\
\hline 12. Revictimization & & & & & & & & & & & & - \\
\hline
\end{tabular}

Note: ${ }^{\dagger} p<.10, * p \leq .05, * * p \leq .01, * * * p \leq .001$ 
Figure 1

Relations among Characterological Self-Blame, Social Reactions, PTSD Symptom Severity, and Coping

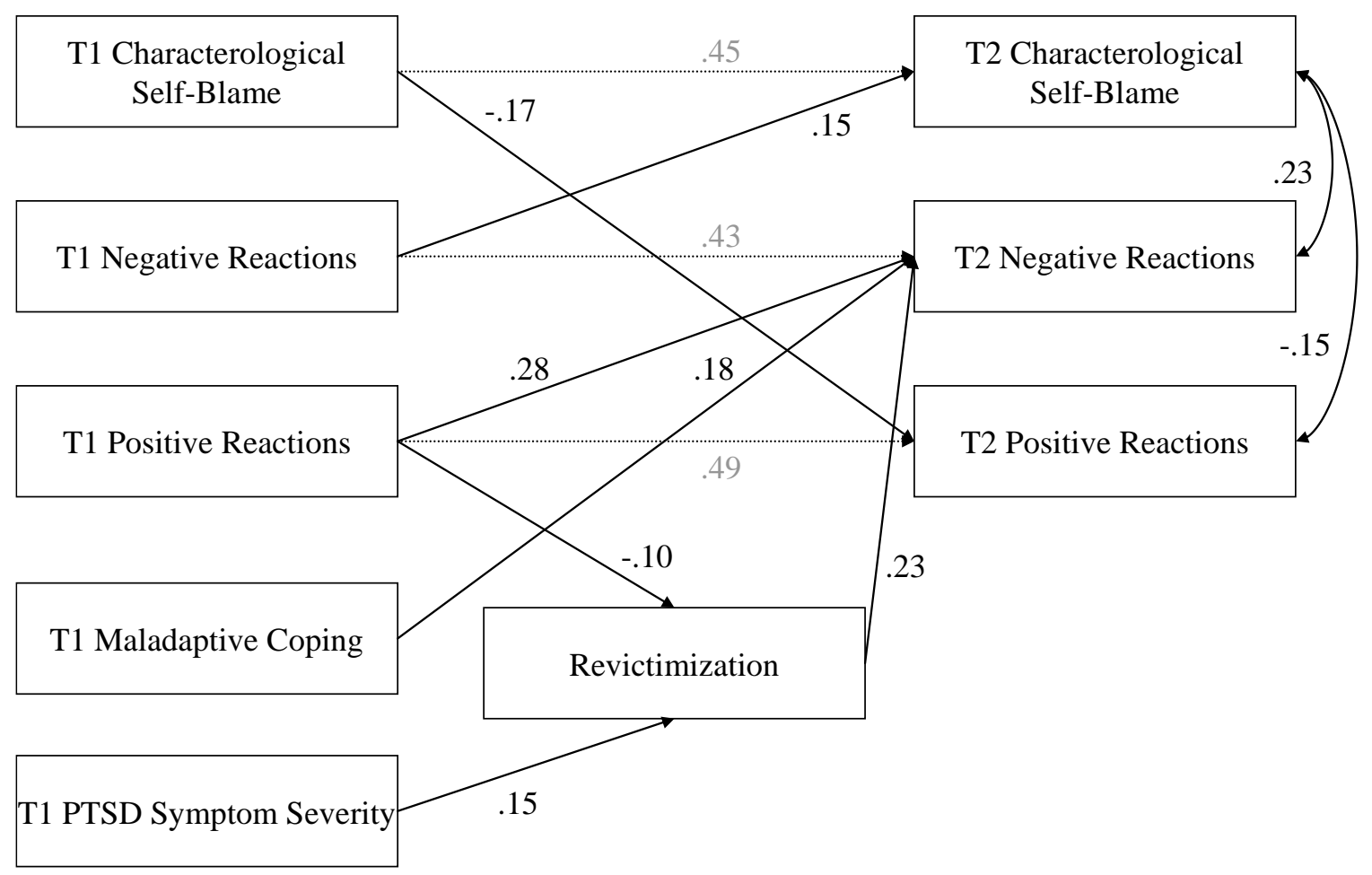

Note. Dashed lines link variables measured at T1 with the same variables measured at T2 to provide information about the relative stability of the variables (Martens \& Haase, 2006). 
Figure 2

Relations among Behavioral Self-Blame, Social Reactions, PTSD Symptom Severity, and Coping

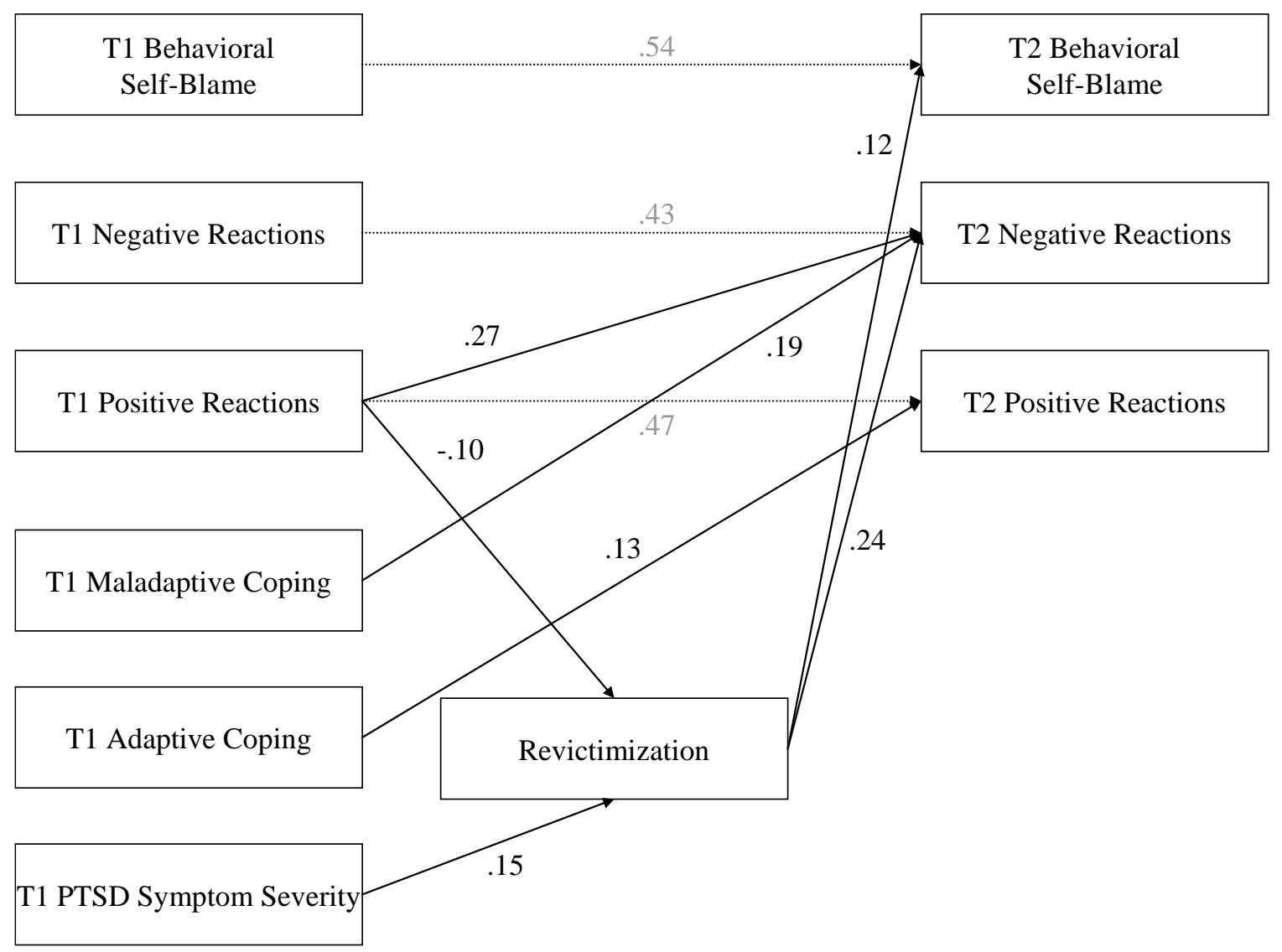

Note. Dashed lines link variables measured at $\mathrm{T} 1$ with the same variables measured at $\mathrm{T} 2$. 